\title{
Spontaneous Expulsion of Ingested Foreign Bodies: Case Series and Review of Literature
}

\author{
Yadav $A K,{ }^{1 *}$ Shrestha $R S,{ }^{1}$ Sharma $R,{ }^{2}$ Khadka $B,{ }^{3}$ Awale $L,{ }^{4}$ Malla $G B^{5}$
}

\section{Affiliation:}

1. Assistant Professor, Department of General Practice \& Emergency Medicine, B. P. Koirala Institute of Health Sciences, Dharan-18, Sunsari, Nepal.

2. House Officer, Department of General Practice \& Emergency Medicine, B. P. Koirala Institute of Health Sciences, Dharan-18, Sunsari, Nepal.

3. Final Year MBBS student, B. P. Koirala Institute of Health Sciences, Dharan-18, Sunsari, Nepal.

4. Division of Gl Surgery, B. P. Koirala Institute of Health Sciences, Dharan-18, Sunsari, Nepal.

5. Head, Department of General Practice \& Emergency Medicine, B. P. Koirala Institute of Health Sciences, Dharan-18, Sunsari, Nepal.

\section{ARTICLE INFO}

\section{Article History}

Received : 31 Aug, 2016

Accepted : 16 Sept, 2016

Published : 20 Dec 2016

(C) Authors retain copyright and grant the journal right of first publication with the work simultaneously licensed under Creative Commons Attribution License CC - BY 4.0 that allows others to share the work with an acknowledgement of the work's authorship and initial publication in this journal.

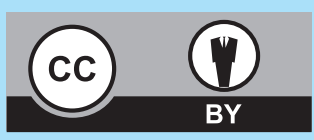

* Corresponding Author

Dr Ajay Kumar Yadav Assistant Professor

Department of General Practice \& Emergency Medicine

B. P. Koirala Institute of Health Science, Dharan, Nepal Email: dr.ajaybpkhihs@gmail.com

\section{Citation}

Yadav AK, Shrestha RS, Sharma R, Khadka B, Awale L, Malla GB. Spontaneous Expulsion of Ingested Foreign Bodies: Case Series and Review of Literature. BJHS 2016; 1 (1) 1: 78-82.

\section{ABSTRACT}

Foreign body ingestion is a commonly seen event in emergencies, usually in children, psychiatric patients, chronic alcoholics, drug abusers and the elderly patients with poor fitting dentures as well as the mentally challenged individuals. While ingestion of foreign bodies into Gastrointestinal Tract (GIT) may be accidental (especially in children), or experimental (anal insertion by adults), it may be purely intentional as in smugglers of illicit drugs, jewels and other valuables so as to evade detection by the security. About, $90 \%$ of ingested foreign bodies pass through the gastrointestinal tract without complications, $10-20 \%$ necessitate endoscopic removal, while only $1 \%$ of them will finally need surgical intervention. In clinical practice we often face the dilemma of choosing the appropriate treatment modality. We present five cases treated in the emergency ward of B P Koirala Institute of Health Sciences, Dharan, Nepal, emphasizing in a "waiting and close observation" policy. Among these cases, all expelled the foreign body spontaneously in their stool without any complications.

\section{KEYWORDS}

Children, coin, foreign bodies, nail 


\section{INTRODUCTION}

There are various types of objects that have been ingested; coins (especially in children) have been the most frequently described objects in the history. ${ }^{1}$ Anatomic and physiologic areas such as cricopharynx, middle esophagus, lower esophageal sphincter, pylorus, ileocaecal valves as well as anal sphincter and pathological conditions like strictures, tumours, diverticulum and hypomotility states like gastroparesis or paralytic ileus sometimes block spontaneous passage of ingested foreign bodies. ${ }^{1}$ Children account for $80 \%$ of ingested foreign bodies, which are usually coins, small toys, crayons or batteries. ${ }^{2}$ Usually, up to $90 \%$ of them pass through the gastrointestinal tract spontaneously and $10 \%$ to $20 \%$ require endoscopic removal, whereas only $1 \%$ requires surgical intervention. ${ }^{3}$ This may be so in children with preexisting $\mathrm{Gl}$ abnormalities such as fistula, gut stenosis and past surgery involving the gut. Such complications include failure to thrive or recurrent aspiration pneumonia, esophageal perforation, crepitations, and pneumomediastinum. ${ }^{4}$ The frequency of bowel movement by the individual will determine the timing of expulsion of the ingested particles or objects. While it may be possible to recover the ingested objects within 24 hours of ingestion, most people will pass the objects after 24 hours. ${ }^{5}$ Objects that are pointed or have

\section{Figure 1 : Nepali one rupee coin measuring $20 \mathrm{~mm}$}

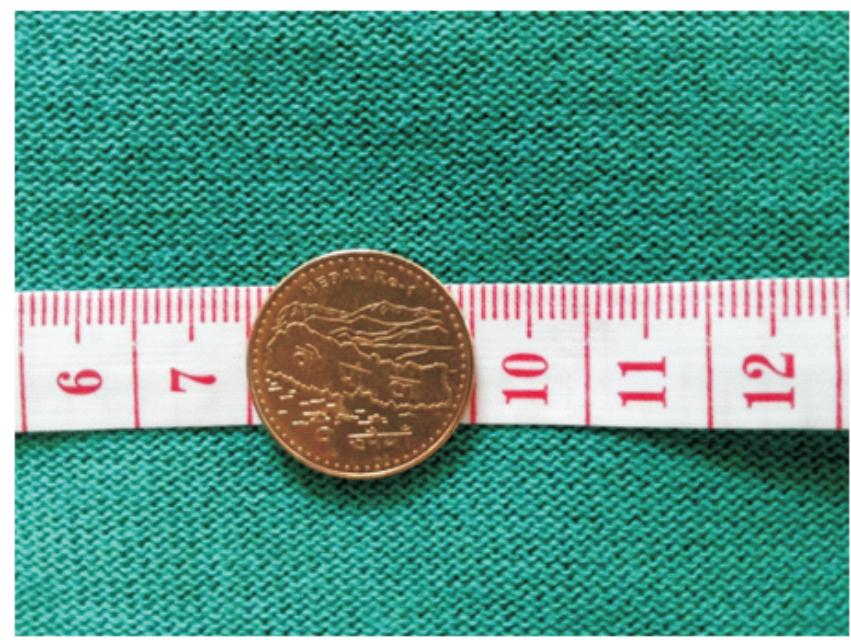

sharp ends may stick or pierce the mucosa and have a relatively slow transit time compared to rounded non pointed objects which are expected to have a relatively shorter transit in the GIT. The time at which an object is ingested may not be known if the patient is a child. A high index of suspicion may be all that might lead to the diagnosis of ingested foreign bodies especially if those items were suddenly found to be missing and a child was present around the place as of that time. ${ }^{5}$ The first investigation usually is an X-ray to localize the site of the ingested foreign body as most ingested foreign bodies are radio-opaque. ${ }^{6}$ We present four cases of ingested foreign bodies among which three were one rupee coin and one were nail which were expelled spontaneously within 24 hours of ingestion without any noticeable complications.

\section{CASE REPORTS}

We present here five cases with ingested foreign body seen in plain X-Ray. Three cases swallowed a Nepali one rupee coin (20 $\mathrm{mm}$ in diameter), one case swallowed an iron nail $(25 \mathrm{~mm}$ in length) and one case swallowed a pendant of a holy thread from temple. (Fig 1 \& 2) The pendant could not be measured as the stool was flushed through the toilet after visual confirmation of the expulsion of the pendant in the stool of the child by the parents.

\section{Figure 2 : Iron nail measuring $\mathbf{2 5} \mathbf{~ m m}$}

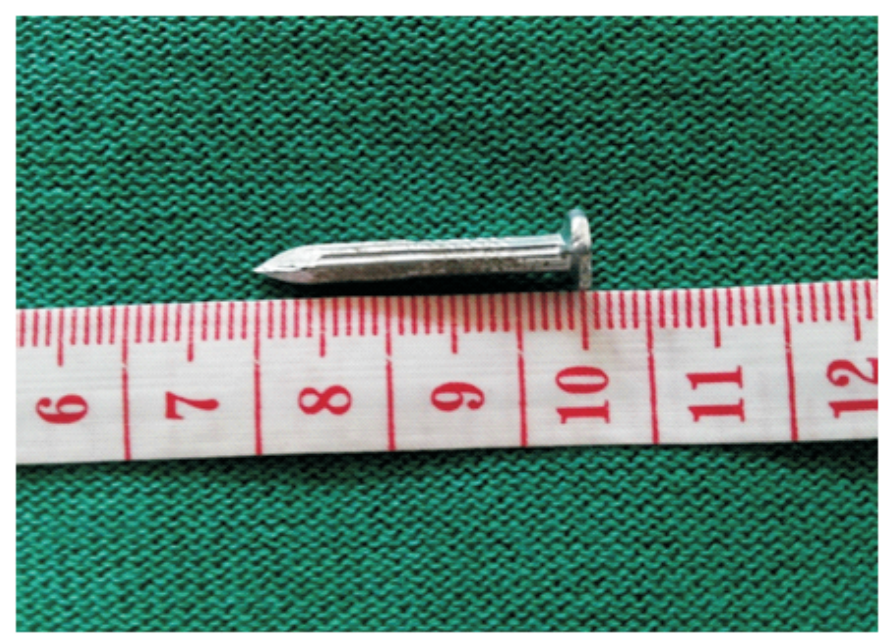




\section{Case 1}

A three year old girl was apparently well and very active with no prior history of any obvious illness. The child was told to be playing with other children holding a rupee coin in her hand, which was accidently ingested. With the elder sister testifying as an eye witness, the parents suspected that the child had ingested the coin. At home, vomiting was induced, which was not successful. She was then rushed to the BPKIHS emergency room by her parents. At the emergency room, the associated complaint was nausea. On examination, the child was asymptomatic, abdomen was soft she was kept on normal soft diet. A plain X-ray of the abdomen revealed a solid opaque round structure in the abdomen (Fig 3). The following day about 18 and half hours after the ingestion of the coin, she passed stool. She passed the coin in the stool without any bleeding or pain.

Figure 3: Plain X-ray abdomen showing a round opacity at level L2 vertebra

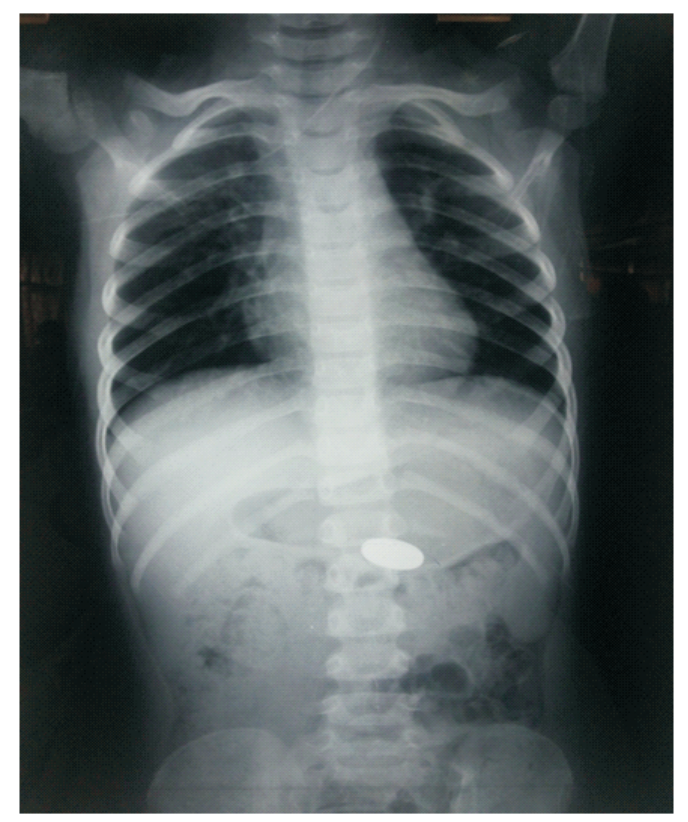

\section{Case 2}

A four year old female child was brought to emergency 20 minute after ingestion of a rupee coin. According to her mother, the child was playing with a one rupee coin when they came to visit her uncle who was admitted in our hospital. After 20 minutes, the mother suspected the child may have swallowed the coin. When the child was asked, the child broke into tears. The child was then taken to the BPKIHS emergency room with a strong suspicion of ingested coin. At the emergency, the child was asymptomatic. On examination vitals were stable. Abdomen examination revealed normal findings. Radiograph of abdomen erect $1 \mathrm{hr}$ after ingestion of foreign body showed a disc shaped foreign body in the stomach at the level of L1 vertebra (Fig 4) With no obvious complaints and symptoms from the child and her mother; normal findings on examination and radiographical findings matching with the history given by the mother, it was decided to wait and watch at the hospital in the observation ward. No intervention was done and the child was given normal diet. Child passed the coin in stool $15 \mathrm{~h}$ after ingestion.

Figure 4: Plain radiograph of the abdomen shows round opacity at level L1 vertebra

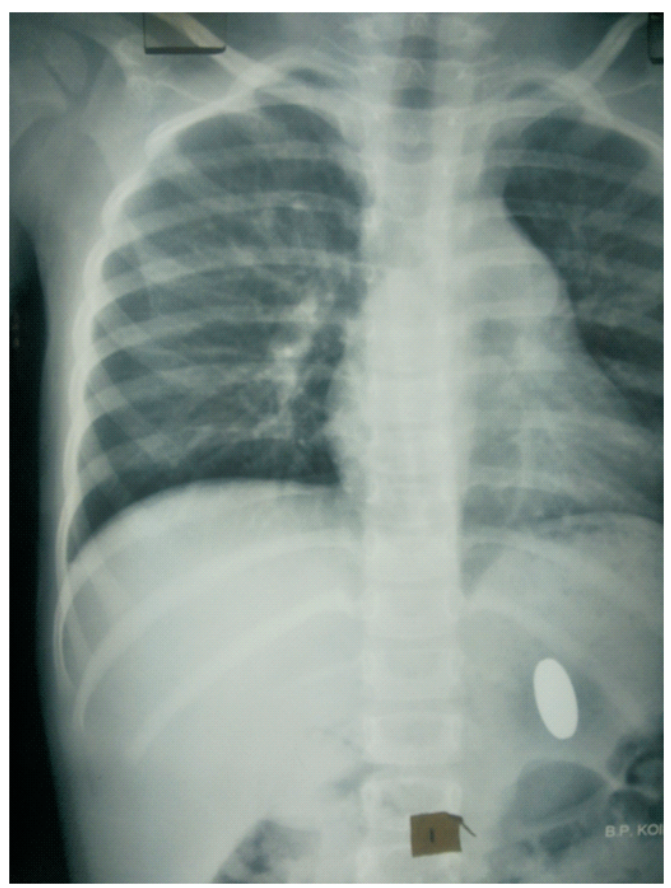

\section{Case 3}

A boy aged three years was brought to our emergency ward by his mother with alleged history of accidentally ingestion of an iron nail about 30 minutes earlier. The child looked normal, and did not complain of anything. On examination, the findings were normal including a soft and non-tender abdomen. Plain X-ray of the abdomen revealed a nail lying in the stomach (Fig 5). With no intervention plan immediately, the child was admitted to hospital with closed observation, and was put on a normal soft diet. Subsequent, four hourly $x-$ ray revealed the iron nail had moving down. The child expressed no symptoms. The child had a well-formed stool and passed the nail after 18 hours of ingestion along with the faeces. A subsequent X-ray of the abdomen was normal, the child was stable and abdomen was soft so, discharged by morning. 
Figure 5: Plain radiograph of abdomen showing nail like opacity at level L2 vertebra

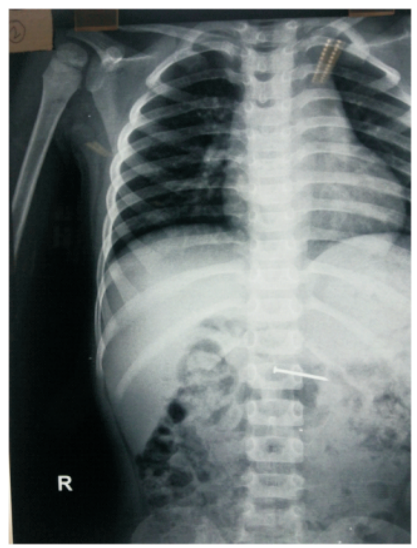

\section{Case 4}

A two year old, male child accidently ingested a rupee coin while playing with coin. After some time child had nausea and coin was missing. Without further delay the child was taken to a nearby hospital where $\mathrm{x}$ - ray chest was done where disc shape radiopaque shadow was noted in upper esophagus (Figure 6) and the patient was referred to our hospital. On examination, no abnormal physical signs detected his abdomen was soft and non-tender. Plain X-ray of the abdomen revealed a coin lying in the stomach after 4 hours. This was taken as a positive finding that the coin was spontaneously moving down the alimentary canal. He was admitted to hospital for observation, and was put on a soft diet. A subsequent $x$ - ray was done after 4 hours which showed that the foreign body had travelled. He passed the coin after 24 hours of ingestion along with stool, ingestion time 6:00 am - expelled at 6 am next day. A subsequent X-ray of the abdomen was normal, the child was stable and abdomen was soft so, discharged by morning.

Figure 6: Plain radiograph showing round radio opaque foreign body at level of the T2 vertebra

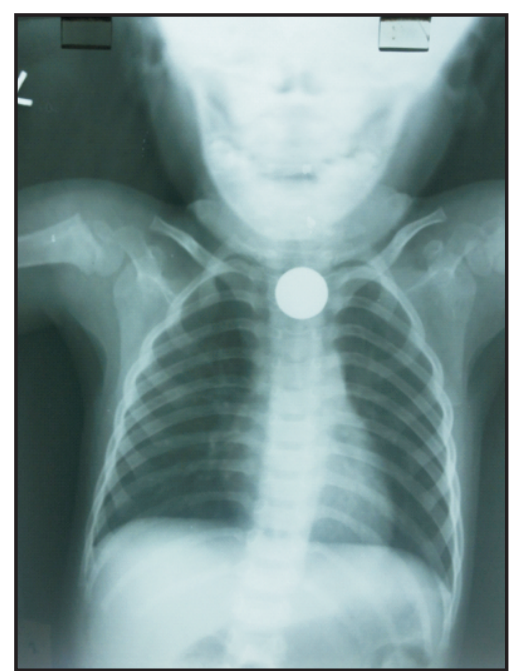

\section{Case 5:}

An 18 months male child from Dharan, Sunsari presented in emergency with alleged history of ingestion of metallic pendant from the holy thread of a temple, about 90 minutes prior to the presentation at the emergency ward of our hospital. The child had no complaint when attended at the emergency. The history matched with the x-ray finding which revealed a locket in the upper abdomen (Figure 7). We explained about the possibility of spontaneous expulsion of the pendant in the feces, the mother of the child expressed that she wishes her child to be kept under observation waiting for the pendant to be expelled spontaneously. On examination abdomen was soft non tender and patient was kept on normal soft diet. Subsequent x-ray of abdomen showing moving down of coin so patient kept on closed observation. After 22 hour he passed out the pendant in stool. A subsequent X-ray of the abdomen was normal, the child was stable and abdomen was soft so, patient was discharged.

\section{Figure 7: Plain radiograph showing a pendant like opacity} in stomach

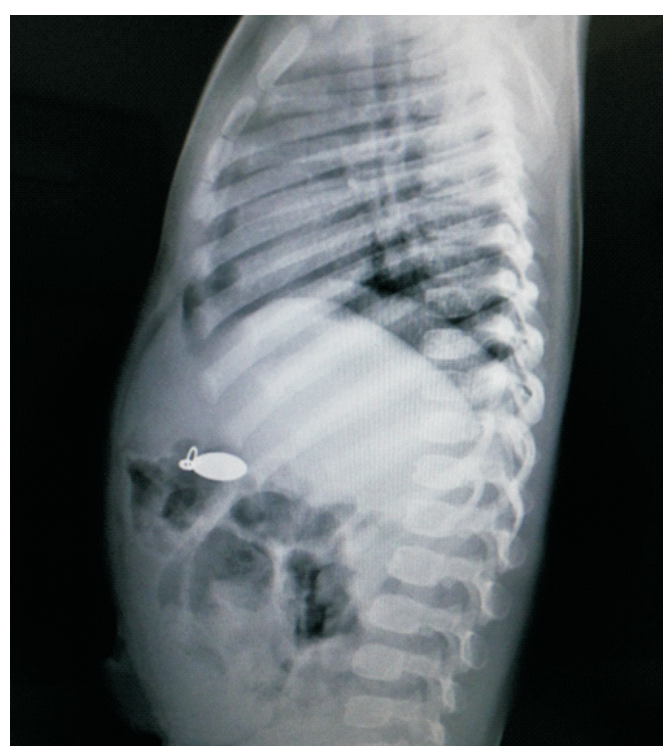

\section{DISCUSSION}

According to the literature, the cases of ingestion of foreign bodies are more common among the infants and very young children compared to older children. ${ }^{7}$ All five cases presented in this paper, belong to children up to four years. Some other children commonly come to medical attention after an episode has been witnessed and reported or the child may present because of signs or symptoms of a complication of ingestion of foreign object not previously witnessed by an adult. $^{8}$ Complications due to ingested foreign objects may occur and in some cases may be life threatening. This may be so in children with preexisting Gl abnormalities such as 
fistula, gut stenosis and past surgery involving the gut. ${ }^{4}$ The two cases presented had chest X-ray for initial evaluation. $64 \%$ of the ingested objects were radiopaque. ${ }^{9}$ Radiographs of the neck, chest or abdomen may be needed while tracking the progress of the ingested object. Though the vast majority of foreign objects is radiopaque and may be seen on a plain film, certain objects such as wooden, plastic, and glass objects as well as bones are not seen and may be missed radiologically by this method. Although up to $90 \%$ of foreign bodies that have passed the esophagus will pass spontaneously, some centers recommends that sharp objects be removed endoscopically before they have passed beyond the duodenal curve because they are more likely to cause complications or require surgical removal. ${ }^{2}$ In our case, the case with ingested nail presented at a stage when the nail had passed down the stomach. Endoscopic removal is done in some places while nothing is done at all in a lot of places. Emergency endoscopic procedures or surgery are not entirely safe and they are froth with some complications and so their advantages should be carefully weighed against nonremoval. In this case series, all the individuals passed their ingested foreign body within the first 24 hours of the presentation at our hospital. While most objects will pass within the first week some may take longer and may need weekly evaluation with careful stool sampling and examination for the objects. Ingested foreign objects causing systemic symptoms such as fever, vomiting and abdominal pain should be considered for emergency removal. ${ }^{5}$

\section{CONCLUSION}

Waiting and close observation is justifiable in the management of ingested foreign bodies, since the vast majority of them pass spontaneously and uneventfully. Decision regarding immediate intervention or conservative approach will require consideration of the level of lodgments \& type of foreign body. Prevention is possible if parents/ guardians exercise control on their children \& are aware of implications of such an event.

\section{ACKNOWLEDGEMENT}

We acknowledge the support from parents of the children and the children themselves for cooperating with us.

\section{REFRENCES}

1. Chen MK, Beierle EA. Gastroin-testinal foreign bodies. Pediatr Ann. $2001 ; 30: 736-42$.

2. Ginsberg GG. Management of ingested foreign objects and food bolus impactions. Gastroi-ntest Endosc 1995; 41:33-38.

3. Hsieh CH, Wang YC, Chen RJ, Fang JF, Lin BC, Hsu YP, Kao JL, Kao YC, Yu PC, Kang SC. Comparison of the Clinical Presentations of Ingested Foreign Bodies Requiring Operative and Nonoperative Management. Int Surg 2005;90: 99-102.

4. Stricker T, Navratil F, Sennhauser FH: Vaginal foreign bodies. J Pediatr Child Health 40:205-7, 2004

5. David Olorunfemi Samue L, Oyewole Fatai Adegboyega, and Okpe Marilyn Ene, "Spontaneous Expulsion of Ingested Foreign Bodies: Case Series and Review of Literature." American Journal of Medical 6. Cheng W, Tam PK. Foreign-body ingestion in children: experience with 1,265 cases. J Pediatr Surg. 1999;34:1472-6.7. O'Hara SM, Donnelly LF, Chuang E, Briner WH, Bisset GS 3rd. Gastric retention of zinc-based pennies: radiographic appearance and hazards. Radiology. Oct 1999;213(1):113-7.

8. Robinson AJ, Bingham J, Thompson RL. Magnet induced perforated appendicitis and ileo-caecal fistula formation. Ulster Med J. Jan 2009;78(1):4-6.

9. Silverberg M, Tillotson R. Case report: esophageal foreign body mistaken for impacted button battery. Pediatr Emerg Care. Apr $2006 ; 22(4): 262-5$. 